\title{
The Use of Information and Communication Technology in Elderly and Patients with Dementia
}

Peter Osvath, Attila Kovacs, Adrienn Boda-Jorg, Tamas Tenyi, Sandor Fekete and Viktor Voros*

Department of Psychiatry and Psychotherapy, University of Pecs, Pecs, Hungary

\begin{abstract}
Modern Information and Communication Technology (ICT) may significantly improve health care of the elderly. In our paper, we summarize the most common ICT tools, and present the results of the most important clinical studies regarding the use of ICT methods in elderly and in patients with dementia. Based on the promising preliminary findings, further studies are needed to develop complex methods that maximize the benefits of ICT tools and to improve the quality of life of the elderly and also to relieve the burden of their relatives and caregivers.
\end{abstract}

Keywords: Information and communication technology (ICT); Elderly; Dementia; Integrated care

\section{Introduction}

In the $21^{\text {st }}$ century, life expectancy increases in advanced societies, and aging populations want to live up to a high age in good health and with high quality of life. In contrast, elderly is faced with more illness and negative consequences of aging, which not only worsen their quality of life, but often lead to loss of self-reliance and thus they increasingly need help from relatives or professional caregivers. An increasing percentage of aging European population suffer from cognitive problems, causing an increasing health and social issue. According to WHO's 2014 report, dementia is one of the biggest public health challenges facing both the rising and present generations [1]. The quality of life of people with cognitive impairment continues to deteriorate when they are simultaneously suffering from other conditions (such as Parkinson's disease, etc.). Symptoms of chronic illnesses considerably undermine everyday quality of life, which poses serious problems, especially in the case of people living alone. Due to the progression of the disease, chronic illnesses have a significant impact on patients' and relatives' lives, and it is a huge mental and physical effort for the caregivers to provide adequate and safe care for the elderly. Thus, there is a major need to organize complex and effective care for the elderly and their relatives. Taking into account the current demographic trends, the financing and sustainability of the care system is becoming more and more challenging both for human and financial resources. Therefore, there is a growing need for complex programs that aim to maintain quality of life and self-reliance as long as possible through the effective co-operation of the different segments of the care system.

\section{Literature Review}

Info-communication explosion resulted in significant changes in health care. Intense research has started in the field of telemedicine (E-health) and telepsychiatry (E-mental health), so that we can learn more about the new tools of healing, its benefits and negative consequences as well as changes in the relationship between doctor and patient. Thanks to the development of the new Information and Communication Technology (ICT), these tools offer a unique opportunity to improve cognitive impairments and elderly care (Table 1). The use of the different ICT tools not only facilitates their everyday life, but also significantly reduces the cost of care [2]. ICT solutions reduce the frequency of emergency care, hospital admissions and hospital stay [3]. They help to preserve the abilities of the elderly, to improve everyday functioning and to preserve self-reliance. Thus, people with dementia may live longer with their loved ones, and in such a case it is not necessary to place them in nursing homes [4].
The potential use of ICT tools is supported by the growing number of elderly people interested in digital culture. They do not only use e-mail, but share photos, make calls on Skype, read and write blogs, and play computer games [2]. These data also demonstrate that ICT tools can play an important role in supporting elderly (Table 1).

Info-communication technologies are used in two main areas of health care. Monitoring of various components of health-related factors (symptoms, complaints, physiological parameters and changes in activity, etc.) not only help in early intervention but also improve health awareness. Telemedicine is used to treat symptoms and disorders; whereby elderly people can improve their health by professional help [5]. Online consultations with professional assistants may be especially important for isolated elderly people with limited mobility.

More and more intensive research has highlighted a number of areas in which the ICT approach can help older people, such as ensuring self-sufficiency; reducing the risk of fall; alleviating the negative consequences of chronic physical and mental illnesses (such as dementia or depression), improving compliance with medication, or solving social isolation and improving quality of life $[2,4]$. Randomized controlled trials (RCT) and meta-analyses that investigate the impact of various information and communication tools among the elderly are summarized in Table 2 [6-22].

First, those techniques need to be mentioned where modern ICT tools help in more effective communication to maintain social relations and to provide more effective psycho-education [7,12]. Interactive tutorials not only provide up-to-date and personalized information to those affected and their caregivers but can also provide online cognitive-behavioural therapy (CBT), problem-solving, relaxation and assertiveness training [13]. These methods considerably alleviate the emotional burden of caregivers, referring to the Dutch "Mastery Over Dementia" program [15]. However, to verify their effectiveness, further controlled trials are required [16].

*Corresponding author: Dr. Voros Viktor, Department of Psychiatry and Psychotherapy, University of Pecs, Pecs, Hungary, Tel: +36-72 535-900/37677; Email: voros.viktor@pte.hu

Received May 29, 2018; Accepted June 05, 2018; Published June 11, 2018

Citation: Osvath P, Kovacs A, Boda-Jorg A, Tenyi T, Fekete S, et al. (2018) The Use of Information and Communication Technology in Elderly and Patients with Dementia. J Gerontol Geriatr Res 7: 475. doi:10.4172/2167-7182.1000475

Copyright: ( 2018 Osvath $\mathrm{P}$, et al. This is an open-access article distributed under the terms of the Creative Commons Attribution License, which permits unrestricted use, distribution, and reproduction in any medium, provided the original author and source are credited. 
Citation: Osvath P, Kovacs A, Boda-Jorg A, Tenyi T, Fekete S, et al. (2018) The Use of Information and Communication Technology in Elderly and Patients with Dementia. J Gerontol Geriatr Res 7: 475. doi:10.4172/2167-7182.1000475

Page 2 of 4

\begin{tabular}{|c|c|c|}
\hline Tools & Use & Advances \\
\hline \multicolumn{3}{|c|}{ Active tools } \\
\hline \multirow{4}{*}{$\begin{array}{l}\text { - PC } \\
\text { - Notebook } \\
\text { - Tablet } \\
\text { - Smartphone }\end{array}$} & $\begin{array}{l}\text { - Online communication } \\
\text { - Continuous and intensive contact with family members }\end{array}$ & $\begin{array}{l}\text { - Reducing isolation } \\
\text { - Increasing the sense of security } \\
\text { - Strengthening family relations and friendships }\end{array}$ \\
\hline & - Telemedicine methods & $\begin{array}{l}\text { - Online help and counselling } \\
\text { - Early treatment and keeping in touch (especially in case of } \\
\text { disability) } \\
\text { - Supplementing doctor-patient relationship } \\
\text { - Improving compliance } \\
\text { - Recognizing early signs of deterioration }\end{array}$ \\
\hline & $\begin{array}{l}\text { - Psychoeducation } \\
\text { - Interactive tutorials } \\
\text { - Cognitive, memory, problem solving, relaxation and } \\
\quad \text { assertiveness training }\end{array}$ & $\begin{array}{l}\text { - Information on disease and treatment } \\
\text { - Improving prevention and health-conscious behavior } \\
\text { - Maintaining physical and mental balance }\end{array}$ \\
\hline & - Online self-help communities & - Strengthening the social network \\
\hline - PC games & $\begin{array}{l}\text { - Fun pastime } \\
\text { - Improving and testing cognitive skills }\end{array}$ & - Early detection of cognitive decline \\
\hline \multicolumn{3}{|c|}{ Passive tools } \\
\hline $\begin{array}{l}\text { - Smart watch } \\
\text { - Smart bracelet } \\
\text { - Sensors }\end{array}$ & $\begin{array}{l}\text { - Tele-monitoring } \\
\text { - Following physiological parameters (blood pressure, heart } \\
\text { rate, oxygenation, respiratory rate, body temperature, } \\
\text { skin resistance, etc.) } \\
\text { - Sleep, movement, activity measurement } \\
\text { - Localization }\end{array}$ & $\begin{array}{l}\text { - Increasing health awareness } \\
\text { - Promoting a healthy lifestyle (exercise, daily activity, nutrition, } \\
\text { sleep) } \\
\text { - Increasing autonomy and security } \\
\text { - Tracking changes in body functions } \\
\text { - Early detection of state deterioration and emergency alarm } \\
\text { - Reducing the risk of fall } \\
\text { - Recognizing and preventing wandering }\end{array}$ \\
\hline - Security equipment & $\begin{array}{l}\text { - Binary sensors } \\
\text { - Smoke and fire detectors } \\
\text { - Motion detector } \\
\text { - Security webcams }\end{array}$ & $\begin{array}{l}\text { - Creating a safe environment } \\
\text { - Online surveillance } \\
\text { - Decreasing caregivers' burden } \\
\text { - Stress reduction }\end{array}$ \\
\hline $\begin{array}{l}\text { - Equipment compensating } \\
\text { the loss of function }\end{array}$ & $\begin{array}{l}\text { - Robot butler } \\
\text { - Programs helping with orientation, planning and guiding }\end{array}$ & $\begin{array}{l}\text { - Facilitating self-sufficiency } \\
\text { - Promoting daily activity } \\
\text { - Making functioning and transport more secure }\end{array}$ \\
\hline
\end{tabular}

Table 1: Use of information and communication tools in elderly.

\begin{tabular}{|c|c|c|c|c|}
\hline Reference & Aim & Sample & Method & Result \\
\hline \multicolumn{5}{|c|}{ Other studies } \\
\hline Chiu and Eysenbach [7] & $\begin{array}{l}\text { Examination of the applicability } \\
\text { of web psychoeducation and } \\
\text { intervention }\end{array}$ & $\begin{array}{l}\text { Family members caring for } \\
\text { patients with dementia ( } 14 \\
\text { people) }\end{array}$ & In-depth qualitative analysis & $\begin{array}{l}\text { The use of interventions is } \\
\text { influenced by the attitudes } \\
\text { and needs of the carer, the } \\
\text { characteristics of the ICT } \\
\text { tools and the method of the } \\
\text { intervention }\end{array}$ \\
\hline Perala [14] & $\begin{array}{l}\text { Impact of ICT tools on security } \\
\text { and preventing wandering }\end{array}$ & $\begin{array}{l}\text { Patients with Alzheimer's } \\
\text { Dementia (32 people) }\end{array}$ & 3 years follow-up & $\begin{array}{l}\text { Home-based devices for } \\
\text { monitoring and locating } \\
\text { increased security, self- } \\
\text { sufficiency and improved quality } \\
\text { of life (primarily useful in the } \\
\text { early stages of dementia) }\end{array}$ \\
\hline Schaller [9] & $\begin{array}{l}\text { Interactive web interface } \\
\text { (European Health Monitor } \\
\text { Dementia Portal) }\end{array}$ & $\begin{array}{l}\text { Caregivers ( } 6 \text { people) and } \\
\text { relatives ( } 26 \text { people) of patients } \\
\text { with Alzheimer's dementia }\end{array}$ & $\begin{array}{l}\text { A 12-week questionnaire review } \\
\text { of the usage of the portal }\end{array}$ & $\begin{array}{l}\text { Improved access to } \\
\text { personalized information, co- } \\
\text { operation between caregivers, } \\
\text { more access to healthcare } \\
\text { (caregivers' burden and quality } \\
\text { of life remained unchanged) }\end{array}$ \\
\hline \multicolumn{5}{|c|}{ Randomized controlled trials (RCTs) } \\
\hline Davison [19] & $\begin{array}{l}\text { Examining the application of } \\
\text { a personalized multimedia } \\
\text { program (Memory Box) for } \\
\text { agitated behavior }\end{array}$ & $\begin{array}{l}\text { Patients with mild to moderate } \\
\text { and severe dementia living in } \\
\text { elderly home ( } 11 \text { people) }\end{array}$ & RCT (8-week trial) & $\begin{array}{l}\text { Reduction of anxiety and } \\
\text { depression symptoms }\end{array}$ \\
\hline Bloom [15] & $\begin{array}{l}\text { Internet psycho education, } \\
\text { cognitive behavior therapy, } \\
\text { problem-solving training, } \\
\text { relaxation, and assertiveness } \\
\text { training }\end{array}$ & $\begin{array}{l}\text { Caregivers of patients with } \\
\text { dementia ( } 245 \text { people) }\end{array}$ & RCT (8 occasions + follow-up) & $\begin{array}{l}\text { Reduction of anxiety and } \\
\text { depression symptoms }\end{array}$ \\
\hline \multicolumn{5}{|c|}{ Meta-analyses } \\
\hline Egan [16] & $\begin{array}{c}\text { Online help programs } \\
\text { (psychoeducation, problem- } \\
\text { solving training, psychological } \\
\text { support) }\end{array}$ & $\begin{array}{l}\text { Caregivers of patients with } \\
\text { dementia }\end{array}$ & Meta-analysis (4 studies) & $\begin{array}{l}\text { Possible but not proven positive } \\
\text { effect on mental health, coping } \\
\text { and quality of life }\end{array}$ \\
\hline
\end{tabular}




\begin{tabular}{|c|c|c|c|c|}
\hline Martinez-Alcalá [8] & $\begin{array}{l}\text { Possible use of ICT (passive } \\
\text { and active methods) }\end{array}$ & $\begin{array}{c}\text { Patients with Alzheimer's } \\
\text { dementia and their caregivers }\end{array}$ & $\begin{array}{c}\text { Meta-analysis (patients with } \\
\text { Alzheimer's Dementia - } 16 \\
\text { studies, } \\
\text { carers - } 10 \text { studies) }\end{array}$ & $\begin{array}{l}\text { ICT methods improve the } \\
\text { quality of life in both groups; } \\
\text { help to understand the } \\
\text { background and course of the } \\
\text { disease; improve contact with } \\
\text { the patient }\end{array}$ \\
\hline Garcia-Casal [21] & $\begin{array}{l}\text { Examining the effectiveness of } \\
\text { computer cognitive training }\end{array}$ & Patients with dementia & Meta-analysis (20 studies) & $\begin{array}{l}\text { Moderate improvement in } \\
\text { cognitive functions and anxiety; } \\
\text { a slight improvement in } \\
\text { depressive symptoms; the daily } \\
\text { activity was not affected }\end{array}$ \\
\hline
\end{tabular}

Table 2: The impact of information and communication tools on elderly: clinical studies, randomized controlled trials (RCTs) and meta-analyses.

Numerous other methods have also been studied: relaxation or appropriate stimulation, compensate cognitive impairment by applying special applications [9]. With the help of a tablet or with other smart devices, various communication and web programs, games, music, pictures and movies are also used as part of the nonpharmacological treatment of the behavioural symptoms in elderly, such as agitation, irritability, confusion, or depression. These complex methods proved to be effective and safe even in the case of more severe cognitive decline [10]. Those applications may be particularly effective that use family members' customized experiences (Memory Box). This not only reduced agitation, depression and anxiety symptoms, but also significantly improved the quality of life of people with dementia [11]. A special form of memory training is called reminiscence therapy, the "off-line" version is widely used in the non-pharmacological management of dementia. Its purpose is solving social isolation, promoting joyful and stimulating activities, improving self-esteem, and re-structuring family relationships. It can be helpful not only in the recollection of joyful events, but also in the dissolution of negative experiences associated with losses. It has a great advantage not only for the elderly, but also for relatives to help improve their relationship, and for professional helpers to provide a better understanding of the patient [9]. Info-communication technology, such as multimedia devices (video, music, pictures, narration with or without) or Internet communication, enable personalization of training materials and thus increase the efficiency of the method [12]. Similarly, cognitive training with different ICT tools [13,14], video games [15], sound, text and image recognition [16], or even virtual reality [17] methods were studied. Computer training has improved global cognitive functions and visual-spatial abilities not only for mild cognitive decline but also for dementia. Computerized neuro-cognitive training to improve memory was even more effective when customized methods were used [18]. It is to highlight that computer games can be used not only to recognize cognitive functions, but can also assist in early detection of dementia, as cost-effective and user-friendly screening tests [19].

The other large group includes the tools that support the everyday activities of the elderly, including their physical and social activities. Various reminders, fall detectors, or other emergency situation sensors included in this group of ICT tools. Electronic memory assistants may also provide advice on doing everyday activities. Sensory techniques for monitoring the status of patients also play an important role. They can not only measure the most common physiological parameters (such as blood pressure, heart rate, oxygen saturation, galvanic skin response), but can also detect the patient's movement and activity [5].

Intensive research is also taking place in the field of how ICT tools can reduce the negative consequences of dementia. One of the most common and most dangerous of these is wandering. Several studies have shown that different sensors (such as door opening sensors) and GPS-based trackers are a significant step forward in preventing this [20]. Using this method can reduce the risk of wandering [21], and it is much easier to find the missing person [22]. Other sensors, such as smoke and fire detectors, motion detector lighting, are also involved in the development of safe-home for people with dementia [21]. Various security devices (e.g. smoke detectors, door opener sensors, electric shock protection, water and air temperature control, motion and activity sensors, security cameras, etc.), other devices (robot butlers - doing housework, bathing, eating), social activity programs (telemedicine, email, or on-line connections) and cognitive function maintenance features (e.g. reality-orientation and memory training) are most commonly used. ICT tools like these help patients learn the most important information about themselves and their surroundings, such as spatial and timely information, important daily activities and events and names [2]. It appears that, irrespective of the technology used, the use of the devices is not so much limited by technical problems but by the cognitive impairment of users and can therefore be used effectively in the early phase of dementia [21]. This implies the importance of early recognition, as learning the use of ICT tools can be significantly hampered by the progression of cognitive decline. In the advanced stage of the disease, passive ICT tools have become more common, such as door alarms or various cameras [21].

Today, complex methods are being used to combine different ICT techniques to help the elderly's everyday life. These include, for example, control applications that perceive the patient's activity and facilitate the scheduling activity (such as hand washing) through the designer and the control system [23]. In practice, this means that when, they take an object into their hands, they also get continuous guidance about what they need to do with it [2].

Multifunctional tools that facilitate orientation in the environment inform the user of the most convenient route, maximizing their individual capabilities and needs. During planning, they integrate information about current environmental (weather, traffic information, social programs, etc.) and personal (physical and psychological status, such as stress, fall, loss) state, and, if necessary, flexibly modify planning or even they call for help. This makes the social activity of the elderly easier and secure, in the case of mild and moderate cognitive decline [20] (Table 2).

\section{Discussion}

For the time being, the currently available literature does not separate the specific applicability of ICTs to certain types of dementia (Alzheimer's disease, vascular dementia, Lewy body dementia, Parkinson's disease, etc.) or the severity of dementia (mild, moderate, severe). However, based on clinical knowledge, cognitive games, digital interaction monitoring can be effective primarily in mild cognitive deficits as well as in screening and early detection, while the various sensory and monitoring tools (door opener sensors, fall monitoring, positioning, etc.) can be mainly used in advanced dementias. Furthermore, in Parkinson's disease special motion sensors are used to effectively monitor the patient's current motion performance and the effectiveness of the anti-parkinsonian drug therapy. 
In addition to the many potential benefits of ICTs presented so far, there may be a question of what disadvantages, "side effects" may be, of ICT tools for the elderly population. Technicisation can further increase the isolation of elderly patients and indirectly reduce the personal relations with the family and caregivers. It can also create a false sense of security, whether in caregivers or in family members, so they can even leave the demented patients alone. Additionally, especially with regard to games and on-line applications, it is also important to consider addiction, especially for patients with Parkinson's disease who receive anti-parkinsonian medications that may increase the risk of addiction. Research has also shown that the use of ICT tools is most effective when applied on the basis of a proper theoretical background in the context of a complex integrated care model.

Modern information and communication tools have increasingly become an indispensable part of our everyday life. Research data demonstrate that it can be used effectively to preserve and restore health, not just among young people but also among the elderly. For nowadays, the use of the Internet is widespread among the elderly, but healthcare applications are still less well-known. Summing up the wide range of research findings, it can be concluded that ICT tools have a positive impact on the everyday life of the elderly. They also help to improve health and social functions, maintain quality of life and self-reliance, thus contributing to independent, varied and safe lifestyles. It has also been shown that the use of telemedicine and sensory techniques is particularly effective in improving health and mitigating additional costs by reducing the risk of premature aging and recurrent hospitalizations [4]. So, it is a great help for the elderly to stay in their home without risking themselves. These tools make a significant contribution to reducing the physical and emotional burden of relatives and caregivers, thus improving the quality of life for the whole family.

However, the assessment of the results of current research is severely restricted by the fact that the theoretical framework is often lacking, allowing the use of a personalized combination of ICT tools. In addition, randomized controlled trials evaluating the efficacy of each method are scarcely available. We have no reliable data for their use in the various etiology and severity dementia subgroups and the treatment of associated behavioural and psychological symptoms. For this reason, further, larger studies based on the appropriate theoretical basis are needed to maximize the benefits of the new ICT tools [4]. In ICT research, particular attention should be paid to involve elderly and patients with dementia, as their feedback is indispensable in developing user-friendly tools [24].

\section{Acknowledgments:}

This research has received funding from the European Union's Horizon 2020 research and innovation programme under grant agreement $\mathrm{N}^{\circ} 690090$.

Tamas Tenyi is supported by the National Brain Reserach Program Grant No. NAP KTIA NAP-A-II/12 (2014-2018) and the "Kiválósági Centrum Pályázat".

\section{References}

1. World Alzheimer Report (2014) Dementia and risk reduction. https://www.alz. co.uk/research/world-report-2014

2. Owen L, Tierney R, Rtveladze K, Pritchard C, Nolan K (2015) Cost-utility analysis of an internet and computer training intervention to improve independence and mental wellbeing of older people. Lancet 386 2: 62 .

3. McLean S, Protti D, Sheikh A (2011) Telehealthcare for long term conditions. BMJ 342: 120

4. Tomita MR, Russ LS, Sridhar R, Naughton BJ (2010) Smart home with healthcare technologies for community-dwelling older adults. In: Mahmoud A, Al-Qutayri (eds.) smart home systems. Pp: 139-158.
5. Maresova P, Klimova B (2015) Supporting technologies for old people with dementia: A review. IFAC-Papers On Line 48: 129-134.

6. Khosravia P, Ghapanchia AH (2016) Investigating the effectiveness of technologies applied to assist seniors: A systematic literature review. Int J Medical Informatics 85: 17-26.

7. Chiu TML, Eysenbach G (2011) Theorizing the health service usage behavior of family caregivers: A qualitative study of an internet-based intervention. Int $\mathrm{J}$ Medical Informatics 80: 754-764.

8. Martínez-Alcalá Cl, Pliego-Pastrana $\mathrm{P}$, Rosales-Lagarde A, Lopez-Noguerola JS, Molina-Trinidad EM (2016) Information and communication technologies in the care of the elderly: Systematic review of applications aimed at patients with dementia and caregivers. JMIR Rehabil Assist Technol 3: 6.

9. Schaller S, Marinova-Schmidt V, Setzer M, Kondylakis $H$, Griebel L, et al (2016) Usefulness of a tailored e-health service for informal caregivers and professionals in the dementia treatment and care setting: The e-health monitor dementia portal. JMIR Res Protoc 5: 47.

10. Jackson D, Roberts G, Wu ML, Ford R, Doyle C (2016) A systematic review of the effect of telephone, internet or combined support for carers of people living with Alzheimer's, vascular or mixed dementia in the community. Archives of Gerontology and Geriatrics 66: 218-236.

11. D'Onofrio G, Sancarlo D, Ricciardi F, Panza F, Seripa D (2017) Information and communication technologies for the activities of daily living in older patients with dementia: A systematic review. J Alzheimers Dis 57: 927-935.

12. Petrovic K (2013) Respite and the internet: Accessing care for older adults in the $21^{\text {st }}$ Century. Computers In Human Behavior 29: 2448-2452.

13. Wasilewski MB, Stinsonb JN, Cameron JI (2017) Web-based health interventions for family caregivers of elderly individuals: A scoping review. Int $J$ Medical Informatics 103: 109-138.

14. Perälä S, Mäkelä K, Salmenaho A, Latvala R (2013) Technology for elderly with memory impairment and wandering risk. E-Health Telecommunication Systems and Networks 2: 13-22.

15. Bloom MM, Zarit SH, Zwaaftink RBMG, Cuijpers P (2015) Effectiveness of an internet intervention for family caregivers of people with dementia: Results of a randomized controlled trial. 2: 1.

16. Egan KJ, Pot AM, Albanese E (2015) A systematic review and meta-analysis of internet-based interventions for carers of persons with dementia: More trials needed. Alzheimer's \& Dementia 11: 222.

17. Lazar A (2015) Using technology to engage people with dementia in recreationa activities. Doctor of Philosophy, University of Washington, Washington, USA https://digital.lib.washington.edu/researchworks/bitstream/handle/1773/33607/ Lazar_washington_0250E_15015.pdf?sequence $=1$

18. Vahia IV, Kamat R, Vang C, Posada C, Ross L (2017) Use of tablet devices in the management of agitation among inpatients with dementia: An open-label study. Am J Geriatric Psychiatry 25: 860-864.

19. Davison TE, Nayer K, Coxon S, De Bono A, Eppingstall B et al. (2016) A personalized multimedia device to treat agitated behavior and improve mood in people with dementia: A pilot study. Geriatric Nursing 37: 25-29.

20. Lazar A, Thompson H, Demiris G (2014) A systematic review of the use of technology for reminiscence therapy. Health Educ Behav. 41: 51-61.

21. García-Casal JA, Loizeau A, Csipke E, Franco-Martín M, Perea-Bartolomé MV, et al. (2017) Computer-based cognitive interventions for people living with dementia: A systematic literature review and meta-analysis. Aging and Mental Health 21: 454-467.

22. Hill NTM, Mowszowski L, Naismith SL, Chadwick VL, Valenzuela M, et al. (2017) Computerized cognitive training in older adults with mild cognitive impairment or dementia: A systematic review and meta-analysis. Am J Psychiatry 174: 329-340.

23. Anguera JA, Boccanfuso J, Rintoul JL, Al-Hashimi O, Faraji F, et al. (2013) Video game training enhances cognitive control in older adults. Nature 501: 97-101.

24. Barnes DE, Yaffe K, Belfor N, Jagust WJ, DeCarli C, et al. (2009) Computerbased cognitive training for mild cognitive impairment: Results from a pilot randomized, controlled trial. Alzheimer Dis Assoc Disord 23: 205-210. 